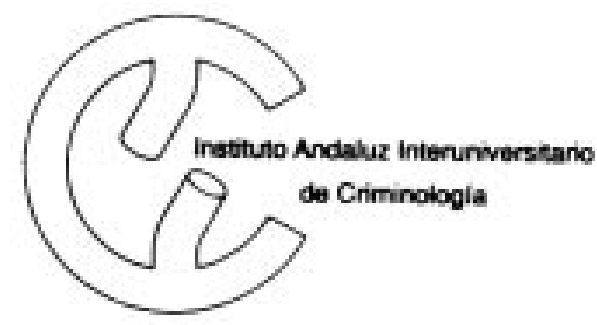

Director: Per Stangeland

Coordinadora: María José Garrido de los Santos

Publicado por la Sección de Málaga del IAIC

Facultad de Derecho, Universidad de Málaga

Campus de Teatinos, 29071 MALAGA

Tel:(95) 2132325 - Fax:(95) 2132242

Depósitolegal:MA857/1996ISSN:1137-2427

Internet: Http: // emn.derecho.uma.es/ crimi

El contacto de la víctima del delito con la Administración de Justicia constituye ya de por sí una fuente importante de perjuicios. Factores como los económicos o la falta de información sobre sus derechos y el proceso penal pueden empeorar esta situación, dificultando el ejercicio de estos derechos y su participación en el proceso. En este boletín se resumen dos pequeños trabajos sobre la participación de la víctima en el proceso penal, realizados en los Juzgados de lo Penal de Málaga. Uno se basa en entrevistas con víctimas citadas para comparecer en el juicio penal. El otro, cuyos resultados se exponen brevemente en la última página de este boletín, es un estudio sobre la personación de la víctima en el procedimiento penal.

\title{
La víctima en el aparato judicial
}

La situación inicial desfavorable de la víctima de un delito puede verse agravada por factores como la falta de información respecto a sus derechos, la mala atención recibida por las instituciones públicas o el mal trato dado por los profesionales. Incluso puede ocurrir que en algunos casos esta victimización secundaria perjudique más a la víctima que el delito mismo.

Desde el punto de vista psicológico, el sentimiento de miedo o inseguridad que el autor del delito crea con sus actos en la víctima se reactiva durante toda la tramitación del proceso, siendo esto tal vez más acusado en el momento del juicio oral.

Desde el punto de vista jurídico, la falta de información respecto al proceso penal de la víctima perjudica la forma de hacer efec-

\section{Derechos de las Víctimas en el Ordenamiento jurídico español}

-Derecho a la tutela efectiva de jueces y tribunales (art.24 C.E).

-Derecho a ser parte en el proceso (arts. 119 y 110 L.E.C.).

-Derecho a la asistencia por abogado y procurador de oficio (art. 119 L.E.C.).

-Protección de los derechos de la víctima por el Ministerio Fiscal (art. 78.1-2 ${ }^{\circ}$ L.E.C.).

-Derecho a la restitución, reparación y resarcimiento civil (art. 100 L.E.C.; arts. 110 y ss.,C.P.).

-Derecho a la tutela de la salud victimal en el orden fíosico y psíquico (art. 43 C.E.).

-Derecho a asociación (art. 22 C.E.).

-Derecho de asistencia (Ley 35/1995; cap II).

-Derecho a ayudas económicas para aquellas víctimas de delitos violentos o de agresión sexual (Ley 35/1995; cap. I).

Fuentes: Herrera (1996); Ley 35/1995.

Vease también la Declaración de los Principios básicos de Justicia para las víctimas de delitos de las Naciones Unidas. Commission on crime prevention and criminal justice (1998)

\section{Autoras:}

Aurora Molina Lizana

Pilar Pérez Candela

Marta Ramirez López

tivos sus derechos.

Desde una perspectiva sociolaboral o económica, la obligación impuesta a la víctima de asistir a todo tipo de actuaciones procesales lleva consigo en muchos casos inconvenientes derivados del cuidado de hijos menores, pérdida de horas o días de trabajo, o cierre del negocio.

Todo ello, sumado a la frecuente insolvencia de sus victimarios y al miedo de posibles represalias por parte del autor del hecho delictivo o su familia, pueden ser, entre otros motivos, causa de la actitud negativa de las víctimas a comunicar a las autoridades la comisión de hechos delictivos y de tener una "mala imagen" de la justicia española.

En este estudio hemos querido acercarnos a este tipo de cuestiones, para conocer el tratamiento de las víctimas de delitos por parte del sistema judicial y la participación de la propia víctima en el proceso.

\section{Boletín Criminológico $N^{\circ} 44 \quad$ Noviembre-Diciembre 1999 Página 1}




\section{Metodología}

El método utilizado ha sido la en trevista semi-estructurada sobre la participación de las víctimas en todas las fases del proceso, con cuestiones referidas tanto al momento de la denuncia como al transcurso del procedimiento y el momento del juicio. El instrumento usado ha tomado como modelo una encuesta sobre la opinión de los usuarios de la justicia en general realizada por Demoscopia y publicada por el Consejo General del Poder Judicial. En la entrevista hemos incluído tanto preguntas cerradas como abiertas, con el objeto de profundizar en las cuestiones abordadas y atender a los aspectos novedosos que pudieran surgir.

Antes de comenzar la realización de las entrevistas se solicitó la autorización del Juez Decano. Esta autorización se envió a los 9 Juzgados de lo Penal para que los Jueces tuvieran la información necesaria sobre el estudio.

El método seguido para localizar a las víctimas y entrevistarlas fue: $1^{\circ}$ ) ir a las Salas en las que se celebraban juicios ese día y leer las listas de juicios y testigos citados; $2^{\circ}$ ) descartar los juicios sin víctima; $3^{\circ}$ ) anotar los nombres de los testigos citados; $4^{\circ}$ ) intentar identificar a los testigos cuando eran llamados por el agente judicial; $5^{\circ}$ ) preguntarles si eran los perjudicados; $6^{\circ}$ ) explicarles el objeto de estudio y pedirles su colaboración. Cabe destacar que se encontraron numerosas dificultades para la realización de las entrevistas, tanto a efectos de reconocer y acceder a las víctimas, como en relación a otros factores como la disposición de un contexto adecuado y de tiempo suficiente antes de su comparecencia en la sala,la coincidencia a la misma hora de juicios en que hay citados testigos en salas diferentes, la suspensión de juicios o la reticencia de algunas personas a responder a ciertas preguntas En total, se realizaron 31 entrevistas entre los meses de febrero a abril de 1999.

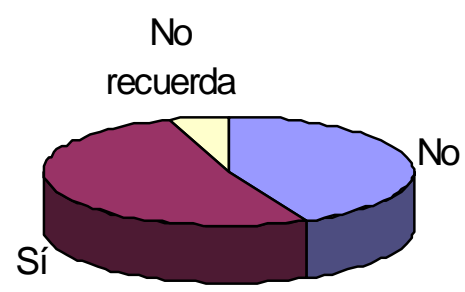

Gráfico 1.¿le informaron sobre sus derechos y obligaciones como perjudicado?

\section{Resultados}

La mayor parte de las personas entrevistadas había sido víctima de delitos contra la propiedad (robos, robos con violencia). Otros delitos eran lesiones, amenazas o coacciones.

La denuncia fue presentada en algo más de un $80 \%$ de los casos en la Policía Nacional; el resto en la Guardia Civil o en el Juzgado. Un $70 \%$ de las personas entrevistadas no tuvo que esperar más de media hora para presentar la denuncia, si bien el resto dijo que tardaron en atenderle una hora o más. Los entrevistados se mostraron satisfechos con el trato recibido por parte del funcionario/policía que les atendió en el momento de la denuncia. Tan sólo una de las personas entrevistadas estaba muy insatisfecha con el trato recibido.

La mayor parte de las víctimas tuvo que acudir al Juzgado a ratificar su denuncia, si bien nos encontramos que 5 manifestaron que bien". no habían sido llamadas para la ratificación. La mayoría estaba satisfecha con el trato recibido por parte del funcionario que le atendió, aunque algunas manifestaron que el trato en determinados momentos fue frío y distante, haciéndoles sentir poco atendidos.

"Satisfactorio, aunque fueron muy deprisa y no me dejaron expresarme

“El día que fuí al Juzgado había mucha gente y comprendo que no pudieran atenderme bien".

“Nada bien, todo a la ligera”.

En cuanto a si le informaron sobre sus derechos y obligaciones, únicamente algo más de la mitad manifestó que le explicaron cuáles eran (gráfica 1).

Por otra parte, sólo a unas pocas de las víctimas entrevistadas, algo menos de un 20\%, les explicaron los pasos que sigue habitualmente un proceso (gráfica

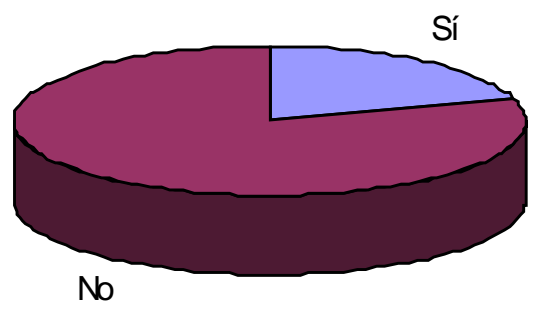

Gráfica 2. ¿Le han explicado los pasos que sigue habitual mente un proceso?

\section{Boletín Criminológico $N^{o} 44$ Noviembre-Diciembre 1999 Página 2}


2). El resto de las víctimas consideró que habría sido apropiado conocer cómo es el proceso, aunque sólo fuese de forma vaga.

“No me han informado de nada."

"Si yo hubiera sabido desde antes qué es lo que pasa en cada momento estaría ahora menos nerviosa".

La mayoría desconocía su derecho a que les abonasen los gastos de desplazamiento y estancia. Sólo unas pocas, seis, conocían dicha posibilidad, de las que únicamente una había solicitado que se los abonasen.

Además, las víctimas preguntadas tampoco conocían la existencia de un Servicio de Asistencia a las Víctimas de delitos, si bien hay que señalar que dicho servicio llevaba tan sólo entre dos y cuatro meses en funcionamiento en el momento del estudio.

Respecto a cuántas veces le habían citado para ir al juzgado, la mitad acudió al juzgado en dos ocasiones: una para ratificar la declaración y otra para declarar en el juicio. Algo más de un $20 \%$ había sido citado en tres ocasiones y casi un $10 \%$ de las personas entrevistadas habían ido al juzgado más de tres veces. La mayoría, un $60 \%$, sabían para qué las citaban, mientras que el resto no lo sabía.

Tan sólo dos personas del total de víctimas entrevistadas habían solicitado que el Juez les recibiera en alguna ocasión. De éstas, una no pudo ver al Juez porque acudió al Juzgado un día en que no pudo recibirla.

Casi todas las víctimas entrevistadas, un $90 \%$, optaron por no personarse como acusación particular. Los motivos más reiterados fueron la falta de información o que preferían dejarlo en manos del fiscal. Varias víctimas se refirieron a los motivos económicos:

"Yo no tengo dinero para pagarme

Más de

tres años

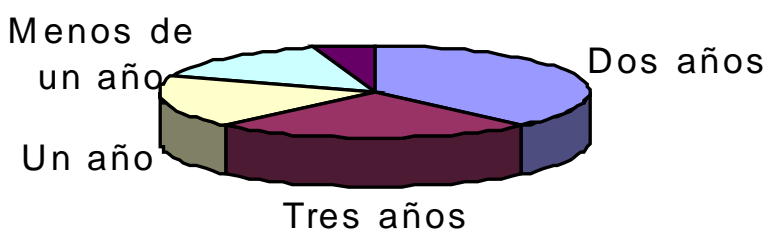

Grafica 3. Tiempo transcurrido entre la denuncia y el juicio

un abogado".

"No, supone mucho gasto".

Respecto al tiempo transcurrido entre la denuncia y el juicio, la mayoría dijo que un año o más, e incluso algo más de la mitad dijo que pasó un periodo de dos años o más; en este sentido cabe destacar que en 6 casos transcurrieron más de 3 años (gráfica 3).

Se preguntó a las personas entrevistadas si tenían miedo a declarar en el juicio, y casi un $60 \%$ contestó que no tenía miedo, pero que les resultaba incómodo o desagradable tener que hacerlo.

\footnotetext{
“No, más bien nervios".

"No, pero no me hace gracia".

"Te da cierto reparo ver cara a cara al delincuente".

"Toda esta situación es incómoda. Me resulta muy violento tener que declarar en el juicio."
}

No obstante, algo más de un $40 \%$ de las víctimas señaló que tenía miedo. De hecho, una de ellas había acudido el día anterior al Juzgado para decir que no quería declarar por miedo; finalmente le ofrecieron poner un biombo al efectuar la declaración, así como esperar dentro de un despacho en lugar de hacerlo en el pasillo con el resto de las personas -entre las que se encontraba el presunto delincuente -.

"Sí, porque en la sala de espera está presente el delincuente y es público."

"Sí, porque puede tomar represalias y agredirme".

"Sí, está delante el procesado y es público."

"Sí, ver cara a cara al delincuente y aguantar las miraditas de toda su familia no le gusta a nadie”.

Si pudiese volver al momento del delito, casi un $80 \%$ volvería a denunciarlo, mientras que el resto no denunciaría de nuevo.

"Yo no volvería a denunciar"

"Cambiaría muchas cosas, no merece la pena denunciar, esto es un lío y una tontería"

"Lo hago para intentar que no vuelva a ocurrir a otras personas, por presionar, por el bien de todos, pero tiene más apoyo el acusado, más información, que el denunciante, se requiere más información.”

Por último, casi un $60 \%$ dijo que no se siente amparada por el sistema judicial. De los comentarios ofrecidos por las víctimas entrevistadas se deduce que existe un descontento generalizado con el funcionamiento del sistema judicial ocasionado por las molestias derivadas de los continuos desplazamientos, la pérdida de la jornada laboral, el relatar los hechos repetidas veces, la suspensión de juicios o la lentitud del trámite judicial.

“Debe ser más rápido y eficaz, debería ser un trato más humano, un poquito de más psicología; en la rueda de reconocimiento salimos todos a la vez, yo y el delincuente, y nos cruzamos en la puerta; de todos sólo han 
cogido a uno.»

"Esto es lento, tedioso, no es de tanta envergadura como para tardar dosaños o más, es muy pesado."

"Tengo que cerrar el negocio cada vez que vengo al juzgado. No entiendo cómo no me han avisado esta vez de que se suspendía el juicio; me podían haber llamado por teléfono."

"Se ha suspendido el juicio. Me han dicho que me volverán a citar otra vez. Me fastidia tener que perder otra mañana para venir aquí."

"Al final el agresor tiene más derechos que la víctima."

"Vengo a declarar como testigo por deber moral, pero tengo mucho miedo y no me siento amparado por la justicia. Espero que no me vuelva a ocurrir algo parecido."

\section{Conclusiones}

Resulta significativo que gran parte de las víctimas no fueran informadas y desconocieran los pasos que sigue el proceso así como sus derechos a la asistencia jurídica gratuita, a ser resarcida por los gastos de desplazamiento o a ser parte en el proceso. Pocas víctimas se mostraron activas en el procedimiento penal.

Por otra parte, si bien la mayoría se encontraba satisfecha con el trato recibido al presentar y al ratificar la denuncia, se muestran insatisfechas con aspectos como la frialdad en el trato, la incomodidad o el miedo a declarar, la falta de atencion o información personalizada, la suspensión de juicios o la lentitud del proceso. Respecto a este último aspecto, la lentitud, en la mayoría de los casos transcurrieron dos años o más entre la denuncia y el juicio. Además, más de la mitad de los entrevistados señaló que no se siente amparado por el sistema judicial. En la misma línea, los resultados de la encuesta a usuarios de la Administración de Justicia (CGPJ, 1997) mostraban que las víctimas valoran la justicia peor que el resto de los usuarios, así como que tienen peor opinión sobre el trato recibido por el juzgado.

Parece necesario, por tanto, dirigir los esfuerzos hacia la búsqueda de soluciones rápidas y eficaces en las que la víctima se pueda sentir verdaderamente amparada por el sistema, mediante una mejor regulación de sus derechos $\mathrm{y}$, sobre todo, mediante un sistema de información que pueda llegar a todos los ciudadanos, que agilice los trámites judiciales. También es importante la creación de un fondo público para el resarcimiento económico de las víctimas.

En este sentido se han conseguido algunos logros (como las indemnizaciones para víctimas de delitos de terrorismo y de delitos violentos o las aperturas de Oficinas de Asistencia a las Víctimas del delito), pero aún queda mucho por hacer. No hay que olvidar que la mayor parte de los delitos co- metidos en nuestro país son delitos contra el patrimonio y en estos casos la víctima es compensada económicamente en muy contadas ocasiones debido a la insolvencia del acusado.

\section{Bibliografía}

ALBARRAN, A.J. (1993): Psicología Forense y Victimología. Madrid, Ed. Siglo XXI.

CGPJ(1997): Encuesta a usuarios de la Administración de Justicia. Madrid.

HERRERA MORENO, M. (1996): La hora

de la víctima. Publicaciones del Instituto de Criminología de la Universidad Complutense de Madrid, EDERSA.

LANZAROTE MARTINEZ, P.A. (1994):

La víctima del delito y el sistema jurídico penal: ¿hacia un sistema de alternativas? Consejo General del Poder Judicial, segunda época, n³4.

STANGELAND, P. (Dir.) (1997): La Criminología aplicada. Cuadernos de Derecho Judicial, Consejo General del Poder Judicial, $\mathrm{n}^{\circ} 15$.

\section{La personación de la víctima en el proceso penal}

Los resultados de un estudio sobre el número de víctimas que se personan en los procedimientos penales, realizado por Antonio Diego Pelaez Díaz y María Cristina López Vera en los tribunales de Málaga, muestran que la víctima ejerce la acusación representada por un abogado en tan sólo un 7,5\% de todos los casos penales. Este dato corresponde a casos tratados en el Juzgado de lo Penal n ${ }^{\circ} 5$ en Málaga, donde la víctima se personó en 54 de los 719 procedimientos que concluyeron en sentencia durante el año 1997. Parece que las víctimas que más se personaron son las que sufrieron estafas y apropiación indebida, delitos que se dirigen frecuentemente contra una empresa y en los que los representantes son sus abogados. En segundo lugar se encuentran las víctimas de accidentes de tráfico, casos en los que suele intervenir la compañía de seguros.

De este estudio inédito se puede concluir que la representación de las víctimas en los juzgados es muy escasa. Sabido es que la víctima del delito puede tratarse como un testigo cualquiera en el procedimiento penal si no se persona en el proceso; si, por el contrario, se persona, puede actuar como acusación particular, presentar sus reclamaciones en el juicio y conseguir información sobre el proceso. Sin embargo, hay muy pocas víctimas que aprovechan esta posibilidad. Es probable que no se trate de desinterés por parte de la víctima, sino de desconocimiento sobre esta opción y, además, de falta de recursos económicos para poder personarse en el conflicto. El establecimiento de un servicio de ayuda a las víctimas pretende remediar esta situación.

\section{Boletín Criminológico $N^{o} 44$ Noviembre-Diciembre 1999 Página 4}

